\title{
The Hills Fuel Poverty Review Interim Report: assessing proposals and implications
}

\author{
Lauren J. Probert*, Victoria Haines and Dennis L. Loveday \\ Loughborough University
}

\section{Summary}

The Hills Fuel Poverty Review has been commissioned by the United Kingdom coalition government to review the definition and targets used to guide the alleviation of fuel poverty in England, as mandated by the Warm Homes and Energy Conservation Act 2000. The interim report was published on 19 October 2011 and addressed questions relating to the definition and measurement of fuel poverty. The final report, due in early 2012, will make further recommendations as to appropriate policy responses. This paper reviews the interim report, placing proposals within the context of the ongoing debate around fuel poverty and its alleviation, and offering commentary as to the implications for policy.

Keywords: fuel poverty; deprivation; housing; indicators.

\section{Background}

Fuel poverty was first isolated as a social problem in the 1970s, when steep fuel price rises caused by the oil crisis of 1973 were observed to be creating financial pressures that impeded households from effectively heating their homes (see Bradshaw and Hutton, 1983). Further work by Boardman (1991) argued that fuel poverty is different from income poverty because of 'the crucial role of housing stocks - the house, heating system and other energy using equipment' (p. 221). That is, some households are subject to a fundamental cost disadvantage when heating their home because technical inefficiencies inherent in the dwelling make it difficult to create and retain warmth. For example, the dwelling might be poorly insulated or have an underperforming boiler. This presents a particular concern in the United Kingdom, where there exists a proliferation of inefficient dwellings and a cold, damp climate. Boardman argued that government had a responsibility to intervene in order to improve the quality of the national housing stock.

Despite inspiring the establishment of issue-specific interest groups including National Energy Action and the National Right to Fuel Campaign, fuel poverty did not become a formal legislative concern until the passing of the Warm Homes and Energy Conservation Act 2000 (WHECA). This required authorities in England and Wales to 
prepare 'a strategy setting out the authority's policies for ensuring, by means including the taking of measures to ensure the efficient use of energy, that as far as reasonably practicable persons do not live in fuel poverty.' The Act offers the definition that 'a person is to be regarded as living "in fuel poverty" if he is a member of a household living on a lower income in a home which cannot be kept warm at reasonable cost.' This core definition is broad, and the Act allows that these parameters may be further refined to facilitate policy implementation.

A public consultation ensued, and the UK Fuel Poverty Strategy was published in 2001 (DTI, 2001). This established the interim target that fuel poverty be eradicated in vulnerable households in England by 2010; the terms of WHECA required the target date for fuel poverty eradication to be within fifteen years, resulting in a default target of November 2016. The Strategy also adopted a quantitative definition for monitoring purposes based upon that first proposed by Boardman (1991), whereby fuel poverty is said to exist where a household is required to spend 10 per cent or more of its disposable income on fuel in order to adequately heat the home. The initial Strategy gave few details as to the specific metrics that should be used to model this effectively, but did provide some guidance around core issues identified through the consultation. The actual methodology for modelling fuel poverty, currently applied to the English Housing Survey dataset, has been refined over the past decade and is evaluated on an ongoing basis by the Fuel Poverty Methodology Group (see DECC, 2010), as well as being subjected to a consultation and independent Peer Review in 2004 (see Sefton and Chesshire, 2005).

A number of schemes to facilitate fuel poverty eradication have been developed since WHECA came into force, though several are currently under review following the passage of the Energy Act 2011. Some are Treasury funded, such as Warm Front, Winter Fuel Payments and Cold Weather Payments. Others, such as the Carbon Emissions Reduction Target (CERT), the Community Energy Saving Programme (CESP) and social tariffs, are funded through energy bills. Despite these efforts, fuel poverty levels have been steadily increasing in England since 2004, a trend that can largely be attributed to the impact of rising fuel prices (DECC, 2011). For eradication targets to be met in the context of persistently increasing energy costs, there would need to be a reevaluation of policy to ensure that such dynamics are accounted for both in the focus and extent of interventions. Alternately, it can be argued that the current definition of fuel poverty is oversensitive to fuel price changes and should be amended to neutralise their impact. More generally, fuel poverty alleviation policy has been criticised as being disconnected from evaluation criteria. The existing definition tends to be used purely to monitor progress and not to guide practical implementation, e.g., as a means of discerning which households require support. The result is a disconnection that makes it difficult to understand how targets are to be achieved and may also impede eradication. The Fuel Poverty Advisory Group (FPAG) have repeatedly called, to no avail, for a 'Road Map' to be developed that would set out precisely how the eradication target will be met in practice (FPAG, 2009: 7). Again, plausible solutions could be to reappraise the way in which support is delivered or, alternately, to consider whether the definition of fuel poverty could be adapted to better suit practical application.

Until recently, the core definitional relationship had gone largely uncontested and had been used consistently by government. However, the Spending Review released by the coalition government on 20 October 2010 announced plans to commission an independent review of the fuel poverty definition and targets (HM Treasury, 2010); this was presented within the context of ensuring the more effective use of resources. On 14 March 2011 it was announced that the review would be lead by Professor John Hills, Director of the Centre for Analysis of Social Exclusion at the London School of Economics. Hills summarises the terms of reference for the review as follows: 
p. 163. The Hills Fuel Poverty Review Interim Report: Assessing Proposals and Implications

In essence, the review has been asked to examine fuel poverty from first principles, including its causes and impacts, and to consider whether the current or alternative ways of measuring fuel poverty best assist policy formulation and delivery. (Hills, 2011: 24)

The interim report, concerned primarily with reviewing what fuel poverty is and how it is measured, was published on 19 October 2011. The final report, which is set to consider implications for policy and intervention, is due in early 2012. It should be noted at this stage that the Government is by no means required to accept Hills' findings. Additionally, Hills' remit is only to consider England; the devolved administrations exert individual powers over fuel poverty policy.

This paper presents an analysis of Hills' interim findings, placing them within the context of the ongoing dialogue around fuel poverty eradication. It is not intended to provide a detailed quantitative evaluation of Hills' proposals; rather, it offers an overview of the issues that have arisen in his work to date and commentary as to what the broader implications might be, with the goal of facilitating ongoing discussion around the development and evaluation of fuel poverty eradication policy. The first section offers a brief overview of Hills' methodology and his proposals for alterations to the current definition and measurement of fuel poverty. The second discusses those changes in more depth, placing them within the context of ongoing debates. The following section discusses the impact the proposals might have, if implemented, on policy measures designed to tackle fuel poverty. The final section concludes with some more general reflections on the potential for Hills' recommendations to support the eradication of fuel poverty in England.

\section{Summary of Review Approach and Proposals}

Professor Hills takes a highly systematic approach, adopting an almost experimental design that is indicative of the value ascribed to objectivity throughout the review. Following a review of literature relating to the existing treatment, causes and impacts of fuel poverty, six potential alternatives are selected, modelled and discussed (see Hills, 2011: 110). The first three of these retain features of the existing definition, but with some amendments. These are:

- to take account of the inflexibility of housing costs as an element of household expenditure by removing them from consideration when measuring income

- to make the affordability threshold dynamic by basing it upon twice the median energy bill as a proportion of income and adjusting as appropriate on an annual basis

- to add a supplementary 'fuel poverty gap' indicator that considers the difference, in monetary terms, between the modelled expenditure for a fuel poor household and the expenditure required to remove that household from fuel poverty. This value can then be aggregated nationally to give a measure that goes beyond a 'headcount' consideration of the number of households in fuel poverty, taking account of the extent, or 'depth', of fuel poverty. 
The latter three alternatives examined by Hills constitute more substantial departures from the current conceptualisation of fuel poverty. These are:

- to identify as fuel poor those whose income falls below a set threshold, once modelled fuel (and housing) costs are deducted. Hills' analysis uses a threshold derived from the current official poverty definition, i.e., 60 per cent of median household income after housing and modelled fuel costs are deducted, equivalised for household size and composition

- to identify as fuel poor those households who have low incomes and occupy inefficient dwellings. Hills models this by defining a low income household as one whose equivalised income after housing costs is below 60 per cent of median, and an inefficient dwelling as one where energy performance rating according to the Standard Assessment Procedure (SAP) is below median

- to adopt a markedly different sort of indicator, considering fuel poverty subjectively by deeming the fuel poor to be those who self-report not being able to keep warm affordably, i.e., when asked as part of a national survey.

Hills establishes in the early chapters of the review (see p. 97), that WHECA's interpretation of fuel poverty captures the core relationship and intention effectively, in that:

a person is to be regarded as living "in fuel poverty" if he is a member of a household living on a lower income in a home which cannot be kept warm at reasonable cost. (WHECA)

This provides the foundation for Hills' proposed solution of a 'low income-high costs' indicator for fuel poverty measurement (p. 135). In the concluding chapters, Hills proposes and discusses a new definition of fuel poverty whereby:

households would be considered fuel poor where: (a) they had required costs that were above the median level; and (b) were they to spend that amount, they would be left with a residual income below the poverty line. (p. 136-137)

In addition, Hills proposes a number of other adjustments and additions to the way in which factors relating to fuel poverty are currently modelled (see p. 137-139). These are largely founded upon his analysis of the six alternatives discussed previously, and include:

- measuring household incomes after housing costs have been accounted for

- equivalising incomes based upon household size and composition

- equivalising bills, again based upon household size and composition

- adding a supplementary 'fuel poverty gap' indicator as before, though with the variation of considering the gap between the modelled and median expenditure.

Under Hills' proposals, the number of households identified as fuel poor in 2009 the most recently modelled year at time of publication - would decrease from 4 million under the current definition, down to 2.7 million (Hills, 2011). 
p. 165. The Hills Fuel Poverty Review Interim Report: Assessing Proposals and Implications

\section{Discussion}

The measurement of fuel poverty requires consideration of both subjective and objective factors. The extent to which certain types of dwelling require more energy than others to maintain a prescribed heating regime can be demonstrated via building energy modelling techniques. The broad distribution of dwelling efficiencies within the housing stock of the United Kingdom can also be conclusively shown. That the problem under consideration exists as an objective fact likely contributed to WHECA's relatively untroubled passage through parliament. The notion that the state has a role to play here is more subjective, however, when this was put to parliament, the intention to make the housing stock more efficient proved broadly popular with left- and rightwingers alike. This is evidenced in the following statement made by David Amess, the Conservative Member of Parliament (MP) who introduced the Bill, during its Second Reading in front of the House of Commons:

Without antagonising Labour Members, let me say as a Conservative that I felt that the term "fuel poverty" sounded rather socialist... I felt rather uncomfortable with that term. As a result, I was happy when it was removed from the Bill... That represents no change of substance to the Bill, as fuel poverty is simply the inability to keep a home warm at reasonable cost. (Hansard, 2000a)

As Amess recognises, though, fuel poverty is socially constructed to express a perceived problem and so there are naturally elements that are based upon ideology, such as the decision as to exactly what level of expenditure on energy should be deemed unacceptable and who should receive support. Later in the same statement he observes that:

It is inevitable that certain terms in the definition, such as "reasonable cost", "lower-income" and even "warm", are somewhat subjective. (Hansard, 2000a)

Considering how Professor Hills met these challenges is fundamental to the analysis of his approach. On the whole, Hills' treatment favours maintaining objectivity where possible. This is made clearest in his praise of the use of modelled - rather than actual - energy use in the current approach; 'it is certainly the case that, being based on modelled energy needs rather than actual energy spending, the indicator offers an important degree of objectivity.' (Hills, 2011: 102); later, 'The most important strength of the current definition is its focus on modelled needs, rather than actual spending.' (p. 108). When faced with more subjective decisions, Hills tends to refer closely to WHECA, most notably the mandate to focus on those who have low incomes and live in inefficient homes. The decision to emphasise objectivity when defining fuel poverty is in some respects an ideological choice in itself. Adopting Hills' approach would alter significantly the way in which fuel poverty is treated as a social problem, as will be discussed in the following sections.

The core conceptualisation of the fuel poverty problem as being framed by three main drivers - low income, energy inefficiency and high fuel prices (Hills, 2011) echoes Boardman's original interpretation (1991). However, Hills makes a major departure in shifting from an absolute threshold (related to a fixed proportion of income) to a relative one (related to median usage). The impact is to make fuel poverty measurement more a matter of identifying those at a comparative disadvantage than of identifying those whose expenditure exceeds that defined as being unacceptable according to an (arguably arbitrary) limit. Boardman based the ten per cent figure on contemporary data that indicated this was approximately the proportion of income spent on energy by households in the lowest three income deciles (see p. 46). This figure was substantiated with reference to work undertaken in 1979 by Isherwood and Hancock, which showed such households were spending twice the median amount on 
fuel, an amount deemed unacceptable. Hills observes that 'one might argue that since the ten per cent threshold was based on a relative comparison to begin with, it should have always been a relative indicator' (2011: 116). Boardman's more recent work confirms that "neither component of the original definition implied the proportion should be fixed' (2010: 49). With the assumed goal that fuel poverty is to be treated objectively as is possible, the removal of a more markedly subjective element of the indicator would seem appropriate. Adoption of a relative indicator would constitute a major shift in the way fuel poverty is conceptualised, with two particularly striking impacts.

Firstly, the impact of fuel prices on fuel poverty levels will be largely eliminated, as any change in required fuel expenditure by households will be moderated by the corresponding change in median expenditure. This is key given that in recent years increasing levels of fuel poverty have been largely attributed to domestic fuel prices rising at a much faster pace than household incomes (DECC, 2011). Whilst these rises do impact on domestic fuel affordability, taking them into account in the current manner does not necessarily constitute an accurate response to the core concerns of WHECA, as it shifts focus away from underlying inequalities inherent in the housing stock as the distinguishing factor. The impact of fuel prices was not always so prominent; at the time that the Warm Homes and Energy Conservation Bill was before parliament, price controls were being removed from the domestic energy market and there was little expectation of significant prices rises in the future:

Does my hon. Friend agree that there is a certain irony in the fact that we are debating the issue against the background of secular falling fuel prices... against the background of those changes, is it not ironic that we are being asked to accept that the problem of alleged fuel poverty is as great as, or greater than, it was? (Statement made by Eric Forth, Conservative MP Bromley and Chislehurst during the House of Commons Second Reading; see Hansard, 2000b)

Moving to the present day, given the recent media attention afforded to energy price rises (see for example Mulholland and Watt, 2011) the broader idea of neutralising the impact of price would seem contentious. The current median unit price of fuel is not universally agreed to be affordable or reflective of an efficiently operating market, and reducing the impact of energy prices on fuel poverty levels could mask a broader need for improvement. Furthermore, under Hills' proposed definition, dramatic - but equally distributed - rises in energy prices would not result in increased levels of fuel poverty, though fuel would undoubtedly be less affordable. However, it can be argued that offsetting the impact of fuel prices is justifiable as an adjustment to the fuel poverty measure in that it removes the extreme emphasis placed on prices by the current measure, thus inhibiting the potential for dramatic inflation of fuel poverty figures and enabling the real progress that has been made in improving the energy efficiency of the housing stock to be acknowledged.

A related concern is the potential for inequitable energy pricing to push some customers further into fuel poverty. Price differentials exist within the energy market and it is recognised that those on lower incomes may be disproportionately penalised; for example, by price discrimination against those who are unable to access online deals and energy switching services, or who are unable to pay by direct debit (see Ofgem, 2008). These sorts of inequalities could be accounted for in Hills' proposed consideration of the fuel poverty gap, which relates required fuel expenditure to median household expenditure, taking account of disproportionate expenditure incurred as a result of inefficient housing or high unit price of fuel. It might be argued that this issue deviates from the core intentions of WHECA. However, Hills' methodology presents a straightforward means by which the impacts of price differentials on those that will be affected most profoundly - those in fuel poverty - can 
be examined. It also opens up a potentially useful tool for those seeking to ensure domestic energy markets are competitive. Hills' approach could refocus the manner in which price discrimination experienced by the fuel poor is considered, enabling this issue to emerge from the shadow cast by generalised increases in energy bills.

However, if this effect is to be achieved, adjustments will need to be made to the methodology used to model fuel poverty statistics. Hills (2011) acknowledges that the current methodology estimates expenditure based only upon region and payment method (something also noted by Sefton and Chesshire, 2005). This, he suggests, could result in fuel poverty being underreported by up to seven per cent (Hills, 2011). Under the proposed methodology, inaccurate modelling of fuel prices could obscure the impacts of price differentials. This interim report discusses the need for additional data to rectify this problem and so it might be expected that further recommendations will be offered in the final report. One potential solution would be to take account of Sefton and Chesshire's earlier recommendation (2005) and adjust the existing English Housing Survey methodology so that more detailed data on actual energy prices paid are collected. This might involve asking participants to report data about their own tariffs, or to allow surveyors to view recent bills. Alternately, the most recent EHS questionnaire asks participants for permission to contact energy suppliers regarding energy usage (DCLG, 2010; this is perhaps with reference to the study alluded to within Hills, 2011), an approach that might feasibly be expanded to include information on tariffs.

A second implication of the proposed change to the fuel poverty definition concerns eradication targets. If fuel poverty is measured relative to median expenditure, then the threshold for being fuel poor will move as fuel poverty is reduced (this would be true of any relative measure of fuel poverty). Under a strict reading, this places it at odds with the requirement of WHECA that the government ensure that 'as far as reasonably practicable persons do not live in fuel poverty'. One possible alteration would be for fuel poverty eradication targets to shift towards eradication of the proposed fuel poverty gap. Whilst not directly proposed by Hills, the potential for this type of measure to be used as a policy instrument was implied in the Energy Act 2010, which considers both reduction of headcount and of the 'extent to which any person is living in fuel poverty' to be valid progress indicators (this is noted by Hills, 2011). The fuel poverty gap is defined as 'the difference between...required costs and the threshold for reasonable costs' (p. 138) where 'reasonable' is defined by Hills as 'median required' (p. 136). This could theoretically be eradicated if all households were paying the same, market-clearing, price per unit for energy, and if all homes were at maximum efficiency potential, i.e., SAP 100 (or potentially even above). In this situation, there would be little reason to discern between fuel poverty and income poverty.

In practice, this outcome is extremely unlikely to be achieved (though the limits of practicability are accepted under WHECA). It is worth noting that the equivalisation of fuel bills has not previously been the focus for consideration in the way that income equivalisation has. However, if we are to consider eradication of the fuel poverty gap as a policy goal, it becomes crucial as otherwise even the most efficient of dwellings couldn't possibly have the gap eradicated without recourse to compensatory economic measures if it fundamentally required above the median quantity of energy (e.g., because of large size) (Hills, 2011). However, it is not entirely clear that the proposed method of equivalisation would necessarily achieve this as it relies in part on an assumed correspondence between household compositions and building energy requirements. It would seem likely that the development of a bespoke methodology, as Hills suggests, may be required; this would likely be a stage of the process at which the input of building engineers would prove extremely valuable. 
Building on the proposed shift to a relative measure, Hills establishes two thresholds that support the previously discussed 'low income-high costs' emphasis; a usage threshold based upon median expenditure, and an income threshold where - at the limit - income less required energy costs is equal to the official poverty line (i.e., 60 per cent of the national median). The shift to a relative measure would make fuel poverty function more as an indicator of inequality, and within this context the choice of placing the threshold in some way relative to the median is apt as a measure of acceptable energy expenditure. However, given that the housing stock of the United Kingdom is of such poor quality, median expenditure still might not be affordable and using a lower multiple than 100 per cent may be more appropriate to support achievement of a desirable standard. However, this judgement is a political one and setting ambitious targets may not appeal to a government seeking to cut spending. With this in mind, and given Hills' emphasis on objectivity, there is a case for focusing first on resolving inequalities.

Interestingly, under the proposed definition, fuel poverty will increase if policies designed to decrease energy expenditure are disproportionally applied to non-fuel poor households, as median expenditure will decrease, driving other households into fuel poverty. For example, a low income household that was initially spending exactly the median amount on fuel would in all likelihood be pushed in to fuel poverty if overall median expenditure subsequently went down, but its individual fuel costs and income did not change. This case illustrates a potential source of friction with environmental policies; one of the drivers of fuel poverty eradication policy in the past has been that activity can support the achievement of carbon reduction goals, a strength that may be lost if Hills' proposals are adopted. However, such an effect could equally function as an indicator of the impacts of regressive policies and, ideally, to discourage their application.

Another potential problem with Hills' interpretation is in the choice to focus on the 'low income-high costs' intersection. Whilst this does make sense in the context of WHECA as a guiding principle, it might also mean that those who are 'high income-high costs' or 'low income-low costs' (as illustrated clearly in Figure 7.6 on Hills, 2011: 142) are not helped, even though they are also likely to be struggling. This concern needs to be accounted for when developing an appropriate application of the definition for implementation purposes.

As a final point for discussion, it is worth considering the two significant changes that Hills proposed to the way in which income is treated in the measurement of fuel poverty. Firstly, Hills endorses a shift to prioritising income after housing costs, rather than before housing costs as is currently the case. This adjustment featured as one of his six modelled amendments, and it is noted that it was a 'common proposal' from those providing evidence to the review (Hills, 2011: 110). This amendment seeks to reflect that funds required for housing do not truly constitute a disposable element of income. This is one of the more subjective elements of any definition; there are arguments for and against either choice, and Boardman (2010: 30) characterises it as a 'political decision primarily about who should be helped most' (the implications of the shift in terms of target demographics are explored in more detail in the next section). Hills, for his part, accepts the argument that income after housing costs is a more accurate representation of disposable income (Hills, 2011).

Secondly, Hills chooses to equivalise incomes in the application of a new measure. Again, this change has long been under consideration given that other poverty measures such as the Houses Below Average Income (HBAI) dataset already routinely equivalise income. In their peer review of the methodology for calculating English fuel poverty levels, Sefton and Chesshire (2005) resolve on balance not to recommend equivalisation in relation to the absolute definition, though the issue is not clear-cut 
and there are concerns that either option might result in an inaccurate representation of the problem. However, Hills argues that with the new threshold-based definition there is a case to equivalise both income and (as discussed earlier) bills.

\section{Policy Implications}

Professor Hills identifies four applications of fuel poverty measurement and related indicators. To paraphrase, these are: to monitor trends and changes in underlying factors; to indicate changes to the extent and depth of fuel poverty; to identify those affected for the purpose of policy design and implementation; and to support the evaluation, assessment and development of interventions (see Hills, 2011: 12). As might be expected, the most profound impact of the changes proposed in the interim report is to the way in which underlying factors impact upon trends and overall levels of fuel poverty. Most crucially, the impact of price rises on fuel poverty numbers has been neutralised and the emphasis switched to the interaction of low income and high usage. As explained, this does represent the precise wording of WHECA more accurately. The shift to a relative definition represents a move to assessment of equity rather than the realisation of an arguably arbitrary target, which is indicative of the general preference for objectivity in Hills' approach.

However, this does mean that should Hills' proposals be accepted, fuel poverty in the strictest sense cannot be eradicated. Hills acknowledges that one of the purposes of the definition is as a tool 'to fulfil WHECA and eradicate fuel poverty as far as reasonably practicable' (p. 96). The terms of reference for the review, also, include development of 'possible formulations for... any associated form of target' (p. 154), as enabled under the non-specific wording of WHECA. Presumably, then, the establishment of terms for the eradication target will be included in the final report; the potential for the fuel poverty gap to be used for this purpose has already been speculatively discussed.

The first two identified applications of fuel poverty measurement broadly relate to the more evaluative aspects of policy. Whilst measurement is undeniably important, fuel poverty alleviation has historically been subject to a dissociation of definition from implementation that could account for the ineffectiveness of delivered measures to date in meeting targets. Hills believes that there should be a link between the implementation programmes delivered on the ground and the definition itself, in the form of measurement' (2011: 94). For targeting purposes, it is likely that applying the new definition as a means of identifying who needs help would not be any easier than it was with the old definition. Hills acknowledges this and states that consideration of possible proxies will be a feature of the final report. A strength of the new definition, however, is that by removing prices for the most part from consideration, an examination of the overlap of low SAP rating and low income (whether by individual or aggregated across a larger area) could provide a closer approximation of definitional fuel poverty than it does currently. Such an indicator could resemble the "low income and low SAP overlap' option modelled by Hills as one of the six alternative measures ( $p$. 124-127). 
It is already clear that a move to the proposed definition would alter the composition of the fuel poor as a group. Most notably, the equivalisation of income and bills would be likely to shift emphasis to larger households, whilst the consideration of After Housing Costs income would result in the inclusion of more households with higher housing costs. In practice, this would move the focus away from older people and towards younger single person households and lone parents (as illustrated at Hills, 2011: 166). This would result in changes to the ways in which socio-demographic proxies may be used to identify the fuel poor for implementation.

An obvious focus for re-evaluation under a changed definition would be Winter Fuel Payments, a tax-free income supplement applied to the majority of those aged over 60 . Even under the current definition, it is widely acknowledged that being of pensionable age constitutes a poor proxy for fuel poverty (Boardman, 2010), yet the Government spent $£ 2.7$ billion on such payments in 2008/9 (Kennedy, 2011). One issue with removing such a benefit is political; reducing the money that goes to older people is likely to be poorly received by voters. Perhaps of greater concern are findings from a recent working paper released by the Institute for Fiscal Studies (Beatty et al., 2011) indicating that households were likely to spend more of the Winter Fuel Allowance on fuel than they would of a similar, unlabelled payment. This is particularly significant given that older people are more susceptible to the negative health impacts related to fuel poverty, and could present a case against suggestions that a continued payment should be treated as a more general 'Winter Pension Supplement' (Boardman 2010; Kennedy, 2011).

Proposed changes to the dynamics that underlie the definition of fuel poverty are likely to alter the ways in which different types of intervention are applied. Given that energy prices would no longer play such a pivotal role, the shift should be towards measures that improve energy efficiency (e.g., insulation and boiler upgrades) and income maximisation (e.g., benefit checks and targeted supplements). Not only would such measures have more of an impact in eradicating fuel poverty, but the new definition would also enhance the potential for progress in delivering such improvements to be presented quantitatively. Under the current methodology, the success of any improvements that are made tends to be masked by the impact of rising prices. This is not to say that energy prices would be ignored entirely under Hills' definition; they would still have an impact where a high tariff were the cause of any gap between median and required expenditure (i.e., the fuel poverty gap). In practice, expanding awareness of median unit prices could be used as a tool to illustrate what consumers should expect from tariffs, and where they might be able to find a better deal. Consideration of inequalities would also be helpful in analysing the application of efficiency measures. Given that the greatest savings can be drawn from 'carbon rich' homes, there has been a tendency in the past for measures that are driven by environmental incentives to be regressive as the funds for such projects have been drawn from energy bills. Under the proposed definition, rising levels of fuel poverty would illustrate this sort of inequality. However, this could be interpreted as placing fuel poverty alleviation at odds with carbon reduction. The Government are currently seeking to drive private investment in energy efficiency measures through provisions introduced by the Energy Act 2011. Following Hills' interpretation, something approaching equality of energy affordability would be almost impossible to achieve unless the investments in efficiency made by higher income households were more than matched by state support for the fuel poor; this seems unlikely under current fiscal policy. 


\section{p. 171. The Hills Fuel Poverty Review Interim Report: Assessing Proposals and Implications}

\section{Conclusions}

This paper has explored some of the ideas raised within the interim report of the ongoing Hills Fuel Poverty Review. Hills' emphasis is upon objectivity and identifying inequalities that exist around the core principles defined in WHECA and by Brenda Boardman's original exploratory work (1991). If we accept this understanding of fuel poverty, the proposed changes represent a cautious improvement on the existing means of definition and measurement, with the potential to support the effective refocusing of resources towards the end goal of fuel poverty eradication. It is a reasoned approach that arguably balances the scale of the problem with the reality of a prevailing political desire to constrain spending. However, it is important that the core goal of fuel poverty eradication - to enable people to remain affordably warm, not simply comparably affordably warm - is not lost. There is a risk that by reconceptualising fuel poverty as an issue of inequality, rather than of inadequacy, the proposed definition strays from the reality of the situation faced by millions of households, one that the state is legally compelled to resolve.

Treating fuel poverty as an equity issue does have the potential to highlight some of the problems that have plagued implementation to date. The neutralisation of the overriding impact of energy prices on fuel poverty statistics is particularly welcomed, though it is suggested that adaptations to the modelling methodology will be needed if some of the more pervasive inequalities are to be accounted for. There are also some concerns that applying the same equivalisation methodology to bills as to incomes may not be appropriate, though further quantitative (and likely technical) analysis would be required to fully explore this issue. The emphasis on the 'low income-high costs' interaction is appropriate to the aims of WHECA, though care needs to be taken to ensure that those with 'Iow income-low costs' and 'high income-high costs' are included as appropriate. The 'sharpness' of the original indicator could have resulted in essentially arbitrary exclusions had it ever been used rigorously as a policy tool, and the proposed definition has the potential to be effectively be harnessed for implementation through the use of proxies linked to income and efficiency. Hills' definition would highlight where policies are regressive, as fuel poverty would increase in line with rising inequalities in fuel expenditure. However, there is also the new potential for a clash with carbon reduction policies that has not existed previously; there is yet to be any sign of the level of investment and structured delivery of measures that will be required to ensure that the fuel poor will not be left behind as higher income households achieve greater efficiencies.

As a final point, it is worth considering the proposed changes from the viewpoint of fuel poverty campaigners. The interim report notes that some consultation respondents felt that focusing on definitional issues could distract from alleviation activity (Hills, 2011). Whilst there is no indication that it was campaigners or practitioners in particular who expressed these views, it is clear that complex methodological adaptations could seem irrelevant to those who are focused on the need simply to make homes more energy efficient, a priority that has not changed. This feeling could also be compounded by the fact that Hills' proposals would, by definition alone, significantly reduce the numbers of households deemed to be in fuel poverty; there is a risk that this could be seen externally as diminishing the scale of the problem. To counteract these impacts, it would be helpful not only for the final report to clarify exactly how eradication is to be achieved under the new definition, but also for the Government to reinforce their commitment to the 2016 target. Whilst the current failure to meet fuel poverty targets necessitates a renewed consideration of objectives, it is difficult to escape that significant resources will be required to bring the national housing stock to the required standard. 


\section{Acknowledgements}

This work was completed as part of doctoral research generously supported through an Industrial CASE studentship provided by the Engineering and Physical Sciences Research Council and E.ON. However, any opinions expressed in this paper are solely those of the authors and do not necessarily represent the views of the sponsors.

* Correspondence address: Lauren Probert, School of Civil and Building Engineering, Loughborough University, Loughborough, Leicestershire, LE11 3TU. Email: I.probert@lboro.ac.uk.

\section{References}

Beatty, T.K.M, Blow, L., Crossley, T.F., O'Dea, C. (2011) Cash by any other name? Evidence on labelling from the UK Winter Fuel Payment. London: IFS. Accessed from: http://www.ifs.org.uk/wps/wp1110.pdf

Boardman, B. (1991) Fuel Poverty: From Cold Homes to Affordable Warmth. London: Belhaven Press.

Boardman, B. (2010) Fixing Fuel Poverty. London: Earthscan.

Bradshaw, J. and Hutton, S. (1983) Social Policy Options and Fuel Poverty. Journal of Economic Psychology, 3, 249-266.

Department for Communities and Local Government (DCLG) (2010) English Housing Survey: Interview Survey Questionnaire - From 2008/2009 onwards. London: DCLG. Accessed from: http://www.communities.gov.uk/documents/housing/pdf/ 1579782.pdf

Department of Energy and Climate Change (DECC) (2010) Fuel Poverty Methodology Handbook. London: DECC. Accessed from: http://www.decc.gov.uk/en/content/ cms/statistics/fuelpov_stats/fuelpov_stats.aspx

Department of Energy and Climate Change (DECC) (2011) Annual Report on Fuel Poverty Statistics 2011 London: DECC. Accessed from: http://www.decc.gov.uk/assets/decc/Statistics/fuelpoverty/2181-annual-reportfuel-poverty-stats-2011.pdf

Department of Trade and Industry (DTI) (2001) The UK Fuel Poverty Strategy. London: DTI. Accessed from: http://www.decc.gov.uk/en/content/cms/what_we_do/ consumers/fuel_poverty/strategy/strategy.aspx

Fuel Poverty Advisory Group (FPAG) (2009) Fuel Poverty Advisory Group for England: Eighth Annual Report 2009. London: DECC. Accessed from: http://www.decc.gov.uk/assets/decc/What\%20we\%20do/Supporting\%20consu mers/Addressing\%20fuel\%20poverty/fpag/186-fpag-8-annual-report-2009.pdf

Hansard (2000a) HC Deb (Session 1999-2000) vol. 354 col. 657, 21 July.

Hansard (2000b) HC Deb (Session 1999-2000) vol. 345 col. 1345, 10 March.

Hills, J. (2011) Fuel Poverty - The problem and its measurement: Interim Report of the Fuel Poverty Review. London: Centre for Analysis of Social Exclusion. Accessed from: http://sticerd.Ise.ac.uk/dps/case/cr/CASEreport69_Full_Report.pdf

HM Treasury (2010) Spending Review 2010. London: TSO. Accessed from: http://cdn.hm-treasury.gov.uk/sr2010_completereport.pdf

Kennedy, S. (2011) House of Commons Library: Winter Fuel Payments Update. London: House of Commons Library. Accessed from: http://www.parliament.uk/briefing-papers/SN06019 
p. 173. The Hills Fuel Poverty Review Interim Report: Assessing Proposals and Implications

Mulholland, H. and Watt, N. (2011) Government sets out plans to tackle rising energy costs. The Guardian, 17 October 2011. Accessed from: http://www.guardian.co.uk/money/2011/oct/17/government-plans-tackleenergy-costs

Ofgem (2008) Energy Supply Probe - Initial Findings Report. London: Ofgem. Accessed from: http://www.ofgem.gov.uk/Markets/RetMkts/ensuppro/Documents1/ Energy\%20Supply\%20Probe\%20-\%20Initial\%20Findings\%20Report.pdf

Sefton, T. and Chesshire, J. (2005) Peer Review of the Methodology for Calculating the Number of Households in Fuel Poverty in England: Final Report to DTI and DEFRA. London: DTI/DEFRA. Accessed from: http://www.decc.gov.uk/assets/ decc/statistics/fuelpoverty/1_20100319143215_e_@@_file16566.pdf 